\title{
To Determine the Effects of the Role of Examinations on the Development of All-Inclusive Learners in Secondary Schools Nyeri County, Kenya
}

\author{
${ }^{1}$ Dr Reuben Nguyo Wachiuri, ${ }^{2}$ Badari Shisha, L.Nonglait, \\ ${ }^{3}$ Jedidah Nyawira Kimathi, \\ ${ }^{1}$ PhD Lecturer Ctholic University of East Africa, Department of Curriculum Nairobi,Kenya \\ ${ }^{2}$ Assistant Professor-Sngap Syiem College \& Research Scholar, Department of Political Science, North Eastern \\ Hills University, Meghalaya,India. \\ ${ }^{3}$ Department of Education, North Eastern Hill University, Meghalaya, India
}

\begin{abstract}
A desirable education system should nurture and develop learner's potential through holistic implementation of the set curriculum. An examination-oriented fails to inculcate practical skills, knowledge, desired values, beliefs and attitudes in learners. The purpose of the study therefore was to assess the implications of examination-oriented system of education on the development of holistic learners in public secondary schools, Nyeri County, Kenya. The objectives of this study were to establish the effects of examinations, school factors, and curriculum implementation on the development of holistic learners in public secondary schools in Nyeri County, Kenya. Questionnaires were administered to teachers, students and principals. The study revealed that an examination-oriented system of education triggered examination malpractices a common phenomenon in secondary schools in Kiambu County. The study recommends that curriculum planners, developers and designers should evaluate content to be taught, its method of delivery and testing to ensure that learning and testing covers the four domains of knowledge. The Ministry of Education should ensure that secondary school curriculum implementation is done appropriately within the time frame of each level. At the same time, teachers should adhere to the appropriate implementation of Secondary School Curriculum in order to avoid examination oriented teaching.
\end{abstract}

\section{Introduction}

Effective schools for the $21^{\text {st }}$ century call for an education system that prepares holistic learners that is transformative but not one that lays a lot of emphasis on examinations which determines the worth of a person. In America the government is emphasizing that teachers must change their traditional methods of teaching into best practices and new roles that promote development of holistic learners. The purely traditional forms, methods and means of education do not meet the current demands of promoting holistic learners nor are the unchanging curricula and pedagogy adequate to meet the demands of a changing society (Kaahwa, 2005). People as both objects and subjects of educational activity experienced the new socioeconomic, ecological, regional, and global changes faster than we educators can keep up by changing the content and process of education (Kappa, 1997). Teachers in America are trained in their totality, which involves purpose, personality, context, and culture which is in turn is inculcated in the learners. Teachers teach for democracy and both teachers and students are technologically literate hence able to interact well and promote a conducive environment for acquisition of skills, values, attitudes all meant for promotion of holistic learning which produces holistic learners.

In Europe, educational change is geared towards equipping learners with the realities of creativity and leadership in all aspects of life. Their target is to build the human civilization on creativity, leadership, innovation, cultural diversity, teambuilding, and technological innovation so as to meet the goals of the changing economy (Ferrari, 2010). Educational changes in Russia is concentrating on a humanistic and democratic society by emphasizing beauty in educational reform; the beauty of nature, of people, of human thought, of relationships, and of things that people make rather than concentrating on examinations alone as a mode of evaluation. Their evaluation is rather comprehensive and integrative that employs performance assessment, projects and portfolios (http:// www.thirteen.org). All this promotes a holistic learner who fits well in the society and makes valuable contributions to the society. The teacher training curriculum should not be more theoretical and examination oriented ignoring a learner-centred education that incorporates reflective practice, including active learning, innovation and partnership building (Cachia \& Punie, 2009). This type of training produces teachers who employ rote learning techniques in their teaching and expect learners to regurgitate what is taught, thereby denying them opportunities to create and recreate knowledge (Capper, 1997). 
According to Omolewa (2003), the continued existence of public examinations in South Africa can be attributed to many factors. Public examinations allocate scarce educational benefits in an objective and unbiased way. However, concerns have been raised that public examinations may discriminate against minorities, rural populations, girls, and students whose first language differs from that of the examination (Kabanji, 2004). These examinations provide a specification of clear goals and standards for teachers and students. The examinations can be used to underpin changes in curriculum and teaching methods, and to maintain national standards. Finally, at the end of secondary schooling, they provide one with legitimate membership in the global international society and facilitate international mobility (Kellaghan, 2004).

The general aims of Education in Kenya strive to foster nationalism, patriotism, and promoting national unity, promoting social, economic, technological and industrial needs for national development and selffulfillment promoting respect for development of Kenya's rich and varied cultures. Whereas aims of Education gear towards furnishing individuals with appropriate knowledge, skills and attitudes, the realization of the goals can only be possible if individuals strive to make deliberate efforts towards acquisition of the same. Pedagogy in this regard should provide opportunities for the fullest development of individual talents and abilities through holistic learning so that the learners adjust well to the rapidly changing environment (Pykett, 2010).

Examinations form one of the most common tool around which entire systems of education revolve. Every educational system uses examination as an indicator of performance and examinations are used to promote learners to the next academic level. Teachers' judgment and examination results forms the grading system by which all the students are classified periodically (Khan et al., 2011). An examination is not only a process of assessing the progress of students but also a motivator that help learners to know their academic strengths and weaknesses. Such examinations are also used to provide teachers with opportunities to try new instructional methods. The use of examinations to promote learners to the next level of education is the reason most of them engage in examination malpractices since examination is also the tool used to facilitate decision making in the performance, educational advancement and job opportunity for an individual (Fasasi, 2006).

\section{Statement of the problem}

According to the Kenya Ministry of Education (2011), examination systems in Kenya tend give insufficient attention to formative monitoring in teaching and learning. As a result, schools ignore aspects of learning that are not tested but yet stipulated in the curriculum. Both the KCPE and KCSE examinations are mainly used for selection and certification, and this makes the systems biased towards further education and training (ibid). The violent reactions by some stakeholders like parents and learners' following underachievement go against the spirit of education. Such reactions indicate situations in which aspirations of the people of Kenya, as expressed in the goals of education, are not being obtained (MoE, 2011).Therefore the study seeks to determine the effects of the role of examinations on the development of all-inclusive learners in secondary schools Nyeri County, Kenya.

\section{Purpose of the study}

The purpose of the study is to determine the effects of the role of examinations on the development of allinclusive learners in secondary schools Nyeri County, Kenya

\section{Objective of the study}

To determine the effects of the role of examinations on the development of all-inclusive learners in secondary schools Nyeri County

\section{Research Question}

What are the effects of the role of examination on the development of all-inclusive learners in secondary schools of Nyeri County

\section{Research Methodology}

The research used descriptive design. Questionnaires were administered to a sample of 20 principals, 50 teacher and 100 students. Stratified simple random sampling was used.

\section{Results and findings}

\section{Respondents' views on the extent to which examinations affect educational practices}

The researcher further sought to establish from the study participants gathered across Nyeri county secondary schools specific educational practices normally affected by examinations and as findings indicate, most teachers $51 \%$, mentioned that cramming was mostly encouraged with the least used practice being acquisition of examinations beforehand by teachers as $2 \%$, mentioned. 
Most principals $50 \%$, mentioned that examinations forced teachers to focus only in areas that may be assessed especially in national examination rather than covering the entire syllabus while $13 \%$, observed that teaching methodologies employed by teachers were informed by the teachers need to ensure students grasped subject contents so as to excel in their examinations. On the other hand, results from students revealed that the most commonly used educational practice within secondary schools in Nyeri County was forcing students to cram subject content as $29 \%$, mentioned while the least used practice was found to be acquiring examination papers beforehand as $4 \%$, mentioned.

Some scholars have called for the abolishment of examinations on grounds that they undermine the very role of education. While discussing teaching and learning in China, Kristofk (2011), noted that the aim of learning focuses solely on passing examinations among the Chinese students. The process begins early; indeed, Formal Chinese education emphasizes testing that begins at age two, and it starts with the initiation of the "three-point life" of home Language. Chinese students have eight classes each school day. Each class has 3 or 4 tests per subject on average, allowing for few extracurricular activities on account of the high volume of daily homework assignments. This highly examination-oriented practice affects the education process, socialization, and ability to learn beyond studying for testing requirements. The researcher points out that the education system in Kenya is so much examination-oriented leaving learners with no time for co-curricular activities which is in support with the research findings.

\section{Responses on the effects of the role of examination on development of all-inclusive learners}

Various statements were used by the researcher to find out the effects examinations had on development of holistic learners and based on the findings, a majority of the principals $70 \%$, strongly agreed that exams forced teachers to focus on passing exams rather than acquisition of knowledge among learners, $63 \%$, strongly agreed that teachers chose the best methodology that allows them to cover the syllabus quickly in order to create time for examinations rather than for enabling learners to master the subject content, majority of the teachers $49 \%$, further strongly agreed that examinations force teachers to teach only the specific areas that may be assessed and neglect covering the entire syllabus that enable the development of holistic learners as required by the educational policies.

As Qi, (2004) observes, ghost-written essays and test questions can be bought, not to mention a hired test taker who will assume the student's identity for the grueling during University entrance examination. Andrew (2010) mentions that there are so many high school students cheating in the examinations because of the nature of the competitive educational system. The observations of the study and support by the scholars reveals that the psychological pressure caused by the examinations constitute the primary drawbacks of examination-oriented education system which does not enhance the development of holistic learners.

The researcher therefore recommends that the examinations should be reformed to develop holistic learners with the desire to achieve the highest aspect of awareness of knowledge and appreciate the value added by such knowledge in their life. Examinations should therefore not be taken to be a custom through which learners should pass to if they are to succeed in life. Schools should not be utilized as the chief method for filtering every generation into individuals who get the prize positions and those who do not. The aspect of filtering wrecks the school's essential capacity of giving education as expressed in the objectives and goals leading to a hopeless situation for the failures.

All Kenyan students in high have one common objective-doing well in examinations in order to make it in life. This calls for memorization of significant volumes of information for the purpose of passing examinations with high grades to join the best courses. Therefore Kenya`s grueling ultra-competitive examinations demands most students to spend years of continual memorization and writing preparing for the exam. Seligmen (2011) posits that youths should be good, smart, healthy and socio-culturally integrated which is referred to as flourishing which the researcher recommends to be incorporated in our schools today to enhance the development of holistic learners. An examination-oriented education system assigns students' aptitude based only on test scores, leading to the marginalization, if not outright disregard of the lower performing students. Kenyan parents and teachers and the society consider scores to be the only evaluating criteria for the students' therefore high scores garner praise whereas low and mediocre scores lead to punishment. In Kenya, scores not people, define worth which should not be the case.

\section{Summary and Recommendations}

The study established that our examination-oriented system of education does not support holistic learning hence ignoring affective domain and psychomotor domain that are required to develop a holistic learner who is responsible and autonomous in the society. According to Amukowa (2013) examination-oriented system of education mutilates individual development and personality growth. This was witnessed from the study where a student committed suicide because of not obtaining a grade A and felt that she had offended the parents by scoring a grade $\mathrm{C}$ in the examination results. 
Likewise, Daniel Goleman (1998), Working with Emotional Intelligence confesses that the drastic mistake is that most training programs have embraced an academic model where our entire system of education is geared towards cognitive skills. He comments that the other domains especially emotional competence in our education system are sorely lacking. Interestingly, he observes that as capacities like empathy or flexibility differ crucially from cognitive abilities; they draw on different areas of the brain. In addition, he notes that intellectual understanding of a competence may be necessary but it is not sufficient in itself to result in behaviour change.

However, the question worth asking is: where is the problem, what can be done about it? With the notion that: the higher you go, the cooler it becomes; it is always challenging to teach the other domains of learning, most especially to adults. Observably, the nursery teachers try as much, the primary level handles a bit and the secondary schools very little if any. The graph keeps diminishing as we climb higher in the education ladder. However, I was warned not to say this regarding all institutions of learning. This is because many schools have sports day; music, dance and drama, debates, speech days and a number of educational tours. This calls for a joint effort by everyone in the society to see the education system of the country to wholeness by not allowing the " tail to wag the dog" that is the examinations should not control what should be taught in schools. Curriculum planners, developers and designers should evaluate content to be taught, its method of delivery and testing to ensure that learning and testing covers the four domains of knowledge. The Ministry of Education should ensure that secondary school curriculum implementation is done appropriately within the time frame of each level. At the same time, teachers should adhere to the appropriate implementation of Secondary School Curriculum in order to avoid examination oriented teaching.

\section{References}

[1]. Coleman J. (1966). Education and Political Development. Berkey, University of California, California, Los Angeles.

[2]. Fasasi, Y.A. (2006).'Quality assurance:, A practical solution to examination malpractices in Nigerian secondary schools. International Journal of African \& American Studies, 5(2), 15-21.

[3]. Kaahwa J.A. (2005). First Time Encounter Narrative of the 31st National Arts Festival held at Grahamstown. South African Theatre Journal. https://handle/10019.1/42892

[4]. Karue, N. \& Amukowa, W. (2013). Analysis of Factors that Lead to Poor Performance in Kenya Certificate of Secondary Examination in Embu District in Kenya.

[5]. http://www.tijoss.com/TIJOSS\%2013th\%20Volume/Amukowa.pdf

[6]. Omolewa, M., \& Kellaghan, T. (2003). Educational evaluation in Africa. In T. Kellaghan \& D.L. Stufflebeam (Eds.), Handbook of educational evaluation (pp. 465-481). Dordrecht: Kluwer Academic

[7]. Republic of Kenya (2011). Report, of the Task Force on A Policy Framework for Education and Training. Nairobi: Government printers 